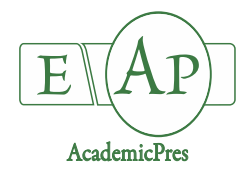

Notulae Botanicae Horti Agrobotanici Cluj-Napoca 48(4):2006-2020

DOI: $10.15835 / 48412082$

Research Article

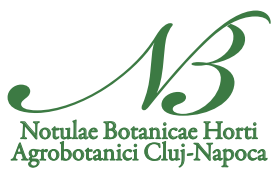

\title{
Effects of mycorrhizal fungi on plant growth, nutrient absorption and phytohormones levels in tea under shading condition
}

\author{
Mufang SUN ${ }^{1}$, Ding YUAN ${ }^{1}$, Xianchun $\mathrm{HU}^{2,3}$, \\ Dejian $\mathrm{ZHANG}^{1,2,3 *}$, Yeyun $\mathrm{LI}^{2 *}$ \\ ${ }^{1}$ Xinyang Agriculture and Forestry University, Henan Key Laboratory of Tea Plant Comprehensive Utilization in South Henan \\ Xinyang, Henan464000,China; xynzsmf@163.com;1846449325@qq.com; \\ zhangdejian0553@126.com (*corresponding author) \\ ${ }^{2}$ Anhui Agricultural University, State Key Laboratory of Tea Plant Biology and Utilization, 130 Changjiang West Road, Hefei, \\ Anhui230036,China;360233834@qq.com; lyy@ahau.edu.cn (*corresponding author) \\ ${ }^{3}$ Yangtze University, College of Horticulture and Gardening, Jingzhou, Hubei 434025, China
}

\begin{abstract}
High temperature and strong light could induce bitterness and astringency of tea (Camellia sinensis (L.) O. Kuntze) in summer. Arbuscular mycorrhizal (AM) fungus and shading could change tea growth surroundings and improve its quality. The present study evaluated the inoculated effects of an arbuscular mycorrhizal fungus (AMF), Glomus etunicatum, on plant growth, root morphology, leaf nutrient status, phytohormones and the relative expression of root CsCPC, CsTTG1, CsAUX1, CsYUCCA1, CsNCED2, Cs GA3OX1,CsDWF4 and CsAOS genes in Camellia sinensis 'Xinyang population' seedlings in sands under shading conditions. After 14 weeks of AMF inoculation, root mycorrhizal colonization ranged from $18.5 \%$ to 48.00\%. AMF inoculation and shading heavily increased plant height, shoot and root biomass, total root length and volume, leaf nutrients content (except $\mathrm{Fe}$ ), respectively. Both mycorrhizal inoculation and shading significantly increased root hair growth respectively, in company with up-regulation gene $C s C P C$ and downregulation gene CsTTG1. Root auxin level and its transport gene CsAUX1 was both up-regulated by mycorrhizal inoculation and shading. Interestingly, auxin biosynthesis gene $C S Y U C C A 1$ has not been affected, which suggested that both mycorrhizal and shading mainly regulate auxin transport but not biosynthesis pathway. The contents of gibberellin (GA) and brassinosteroid (BR) in root were notably increased by mycorrhizal inoculation and shading, accompanied with up-regulation of its biosynthesis genes, CsGA3OXI and $C s D W F 4$. Regarding the growth inhibiting phytohormones abscisic acid (ABA) and jasmonic acid (JA), mycorrhizal inoculation and shading significantly decreased their levels in root, in company with downregulation of biosynthesis genes, CSNCED2 and CsAOS. These results implied that both AMF inoculation and shading could enhance the tea plant stress resistance and increase nutrient absorption, root biomass and the contents of root phytohormones by up-regulating its transport and biosynthesis pathway.
\end{abstract}

Keywords: AMF; nutrient; phytohormones; root hair; shading; tea 


\section{Introduction}

Tea (Camellia sinensis (L.) O. Kuntze) is an important commercial crop consumed in the world, primarily as a beverage made from its leaves after processed (Lin et al., 2010; Shao et al., 2018). As ombrophyte, tea plant growth is often affected by sunlight, temperature, and other environmental factors (Lagad et al., 2013; Sharma and Kayang, 2017). High temperature and strong sunlight could decline tea production and leaves quality during summer (Li et al., 2018b). Arbuscular mycorrhizal are the symbiotic associations formed between soil mycorrhizal fungi and plant roots, can extend their well-developed extraradical hyphae from the roots into growth substrates for water and nutrient acquisition (Hashem et al., 2018; Zou et al., 2019). A complex feedback between host plants and AMF is controlled by their nutrition and physiology, which aims to keep the balance between fungal demands for energy and the plant's need for nutrients (Mathur et al., 2019). Wu et al. (2011a) earlier reported that root traits of trifoliate orange seedlings were significantly improved by AMF inoculation with Glomus mosseae, G. versiforme and Paraglomus occultum. Zou et al. (2017) reported that inoculation with AMF (Diversispora versiformis) significantly increased root hair growth under drought stress. Mathur et al. (2018) has proved that AMF could improve plants' photosynthetic efficacy to resist high temperature stress. These results showed that AMF could regulate root growth, which is very important factor affecting nutrient absorption and plant stress resistance. A study in the past observed that cultivated tea plant existed in AMF, dominated by Acaulospora, Gigaspora, Glomus and Scutellospora (Singh et al., 2008). As reported by Kahneh et al. (2006), inoculation with $G$. etunicatum, $G$. intraradices and G. versiforme significantly increased tea plant growth and leaf nutrient content. AMF-inoculated tea plants exhibited a significantly greater growth performance and higher level of leaf nutrient, as compared with non-AMF control (Shao et al., 2018). It concludes that tea plant is relatively dependent on AMF, whereas the mechanism regarding the AMF improve its growth and enhance resistance is not fully known. Shade-cloth materials are used for protection of ombrophyte against strong sunlight and high temperature damage, such as tea (Tang et al., 2008). However, it isn't yet clear whether AMF present similar effect to shade-cloth materials on tea plant and shade stimulate the soil mycorrhizal hyphal length and subsequent mycorrhizal development.

In addition, the synthetical effects of field climatic factors, physiology, growth and production after using sunshade measures on tea plants have been studied. Tang et al. (2008) reported that field temperature, light intensity and max-temperature were significantly lower under shading treatment. So, field climate improved significantly through shading measures. In practical application, it should choose appropriate shading degrees and shading time according to shade-tolerant characteristics of tea varieties, otherwise it would affect the tea photosynthesis and tea yields. It seems that shading has capacity to improve tea plant growth and the capacity to stand up to high temperature stress.

According to the plant genome sequencing technology and gene identification, root hair initiation and elongation genes, phytohormones transport and biosynthesis genes in plants are well studied. $C P C$ is positive regulation with root hair growth while TTG1 negatively regulate root hair formation, which has been sufficiently studied in Arabidopsis (Tominaga-Wada and Wada, 2016; Long and Schiefelbein, 2020). Indole3 -acetic acid (IAA), the predominant auxin in plants, plays a critical role in plant growth and developmental processes, its biosynthesis and transport has been clearly elucidated by YUCCA (encodes a flavin monooxygenase-like enzyme) and $A U X$ genes (Bennett et al., 1996; Zhao et al., 2001; Hoyerova et al., 2018; Kyoko et al., 2019). The $G A 3 O X 2$ could catalyse the final step in gibberellin (GA) biosynthesis, that convert inactive forms of GA into active $\mathrm{GA}_{1}$ and $\mathrm{GA}_{4}$ which has been extensively studied in planta (Schomburg et al., 2003; Roumeliotis et al., 2013). DWF4, encodes a cytochrome P450 that mediates multiple 22alphahydroxylation steps in brassinosteroid (BR) biosynthesis, which are essential plant-specific steroidal hormones and refers to the growth-promoting steroids found in plants (Choe et al., 1998; Li et al., 2018a). Abscisic acid (ABA), the growth inhibitor, is another plant hormone that has regulatory roles during plant growth and development which biosynthesis requires the cleavage of $\mathrm{C} 40$ carotenoids by 9-cis-epoxycarotenoid dehydrogenase (NCED) to form its direct precursor (xanthoxin) and regulated by NCED1 (Leng et al., 2014; 
Estrada-Melo et al., 2015). Jasmonic acid (JA), as another plant growth inhibitor, plays a regulatory role in plant responses to environmental and developmental cues (Kato-Noguchi and Kobayashi, 2009; Martin et al., 2009; Gutierrez et al., 2012; Lian et al., 2013). Allene oxide synthase (AOS), is the key enzymes involved in jasmonic acid biosynthesis in plants have been separation and identification. Lian et al. (2013) has isloated GhAOS and confirmed that it is the key gene in regulating jasmonic acid biosynthesis in Gladiolus hybridus.

Although these genes have been fully studied in plant kingdom, they involve in regulation of the interaction between inoculation with AMF and shading on tea growth to resist environment stress has not been reported. Furthermore, the physiological and molecular mechanisms of the interaction between AMF and shading on tea growth along with increase nutrient absorption and phytohormones levels to resist environment stress (high temperature) are stills unknown. The aim of this study was to evaluate the effect of AMF on tea growth under shade condition in terms of analyzing changes in root hair growth, root morphology, leaf nutrient concentration, root phytohormones levels and the expression of CsCPC, CsTTG1, CsAUX1, CsYUCCA1, CsNCED2, CsGA3OX1, CsDWF4 and CsAOS.

\section{Materials and Methods}

\section{Experimental design}

The experiment was arranged in a $2^{2}$ factorial completely randomized blocked design: inoculation with or without AMF (Glomus etunicatum) and shade or un-shade. So, there were 4 treatments: Glomus etunicatum and shade $(\mathrm{Ge}+\mathrm{Z})$, only Glomus etunicatum $(\mathrm{Ge}-\mathrm{Z})$, only shade $(\mathrm{CK}+\mathrm{Z})$, none treated $(\mathrm{CK}-\mathrm{Z})$ Each treatment was replicated 6 times, and each replicate had 2 seedlings, for a total of 48 seedlings.

\section{Plant culture}

The AMF strain Glomus etunicatum was provided by the Bank of Glomeromycota in China (BGC) and propagated with the identified fungal spores and white clover (Trifolium repens) for 16 weeks in pots, thereby, containing spores, mycorrhizal hyphae, and infected root segments. This AMF strain had shown greater positive effects on growth responses of tea plants than other AMF (Shao et al., 2018).

Seeds of $C$. sinensis 'Xinyang population', which were provided by the Henan Key Laboratory of Tea Plant Comprehensive Utilization in South Henan, Xinyang Agriculture and Forestry University, were sterilized with $70 \%$ alcohol solutions for $20 \mathrm{~min}$ and then germinated in autoclaved $\left(0.11 \mathrm{MPa}, 121^{\circ} \mathrm{C}, 1 \mathrm{~h}\right)$ sands under the conditions of $26 / 20^{\circ} \mathrm{C}$ day/night temperature and $90 \%$ relative air humidity. After 5 weeks, two-leaf-old tea seedlings with the uniform size were transplanted into a $3.0-\mathrm{L}$ pot containing $3.0 \mathrm{~kg}$ of autoclaved $\left(0.11 \mathrm{MPa}, 121^{\circ} \mathrm{C}, 1 \mathrm{~h}\right)$ sands. The sands collected from the Yangtze River side were sieved through $4 \mathrm{~mm}$, rinsed with distilled water, and autoclaved $\left(0.11 \mathrm{MPa}\right.$ and $\left.121^{\circ} \mathrm{C}\right)$ for $1 \mathrm{~h}$. At transplanting, $200 \mathrm{~g}$ (corresponding to 2200 spores) of mycorrhizal inoculum was applied into the inoculated pot. The non-AMFinoculated treatments were supplied with the same amount of sterilized $\left(0.11 \mathrm{MPa}, 121^{\circ} \mathrm{C}, 1 \mathrm{~h}\right)$ inoculum plus $2 \mathrm{~mL}$ filtrate $(25 \mu \mathrm{m}$ filter) of mycorrhizal inoculum to maintain similar microbial communities, except the AMF spores.

All seedlings were transplanted to a greenhouse in the Campus of Yangtze University for 14 weeks. When seedlings transplanting, shading with black net treatments were begun (none-shade treatment: photosynthetic photon flux density was $1010 \mu \mathrm{mol} / \mathrm{m}^{2} / \mathrm{s}$, day/night temperature $36 / 23{ }^{\circ} \mathrm{C}$, and relative air humidity 60\%; shading with black net: photosynthetic photon flux density was $320 \mu \mathrm{mol} / \mathrm{m}^{2} / \mathrm{s}$, day $/$ night temperature $30 / 23^{\circ} \mathrm{C}$, and relative air humidity $60 \%$ ). Each pot was irrigated with $100 \mathrm{~mL}$ Hoagland solutions $(\mathrm{pH} 4.2)$ every day. The basic culture Hoagland solution (Zhang et al., 2018) was as follows: $4.00 \mathrm{mmol} / \mathrm{L}$ $(\mathrm{mM}) \mathrm{Ca}\left(\mathrm{NO}_{3}\right)_{2} \cdot 4 \mathrm{H}_{2} \mathrm{O}, 6.00 \mathrm{mM} \mathrm{KNO}{ }_{3}, 2.00 \mathrm{mM} \mathrm{MgSO}_{4} \cdot 7 \mathrm{H}_{2} \mathrm{O}, 1.00 \mathrm{mM} \mathrm{NH}_{4} \mathrm{H}_{2} \mathrm{PO}_{4}, 46.00 \mu \mathrm{M} \mathrm{H}_{3} \mathrm{BO}_{3}$, $9.20 \mu \mathrm{mol} / \mathrm{L}(\mu \mathrm{M}) \mathrm{MnCl}_{2} \cdot 4 \mathrm{H}_{2} \mathrm{O}, 0.77 \mu \mathrm{M} \mathrm{ZnSO}_{4} \cdot 7 \mathrm{H}_{2} \mathrm{O}, 0.32 \mu \mathrm{M} \mathrm{CuSO}_{4} \cdot 3 \mathrm{H}_{2} \mathrm{O}, 0.12 \mu \mathrm{M} \mathrm{H}_{2} \mathrm{MoO}_{4}$, and 50 mM EDTA-Fe. 


\section{Variable determinations}

At harvesting, plant height was determined by a ruler. The seedlings were divided into the shoot and the root, whose biomass were measured. Root systems were collected to scan by an Epson Perfection V700 Photo Dual Lens System (J221A, Indonesia), and analyzed by a professional WinRHIZO software in 2007b (Regent Instruments Inc., Quebec, Canada) for morphological traits. The collected roots were frozen immediately at $80^{\circ} \mathrm{C}$ for the analysis of biochemical variables (the levels of phytohormones and the expression of genes). The concentrations of $\mathrm{P}, \mathrm{K}, \mathrm{Ca}, \mathrm{Mg}$, and $\mathrm{Fe}$ in leaves were measured by the inductively complied plasma-atomic emission spectrometry based on the protocol of Shao et al. (2018). Nitrogen (N) concentration of leaf was determined by the Smartchem 200 (Zhang et al., 2017). The levels of phytohormones were determined by liquid chromatography-mass spectrometry (LC-MS) based on the protocol of Kojima (2012).

Root mycorrhizas were stained according to the protocol of Wu et al. (2019) with staining of $0.05 \%$ trypan blue in lactoglycerol. The root mycorrhizal colonization was calculated as the percentage of infected root lengths against total observed root lengths.

The 1-cm-long root hair zones $(2-3 \mathrm{~cm}$ from the root tip) of lateral roots were chosen to measure root hair morphology by Scanning Electron Microscope (SEM, JSM-6391LV, JEOL Co., Japan). These root segments were postfixed overnight in $2.5 \%$ glutaraldehyde with $0.1 \mathrm{M}$ sodium cacodylate buffer $(\mathrm{pH} 7.4)$ and postfixed in 1\% osmium tetroxide for $1 \mathrm{~h}$ (Zhang et al., 2016, 2018). Fixed specimens were dehydrated with increasing concentrations of alcohol. Immediately after dehydration, samples were dried with the critical-point drying (CPD) method (Bray et al., 1993; Zhang et al., 2016, 2018). For each treatment, 9 pictures at 100× were randomly chosen for the measurement of the root hair density, and 9 pictures at $400 \times$ were also randomly chosen for the measurement of the root hair length and diameter using ImageJ (National Institutes of Health, Maryland, USA, http://rsb.info.nih.gov/ij/).

The relative expression of genes in roots was analyzed by real-time quantitative PCR (qRT-PCR). Root total RNA was extracted in $0.5 \mathrm{~g}$ fresh sample (root hair zone: $2-4 \mathrm{~cm}$ from root tip) using a TaKaRa MiniBEST Plant RNA Extraction Kit (9769, Takara Bio. Inc, Japan). RNA samples were reverse-transcribed using the PrimeScript ${ }^{\mathrm{TM}}$ RT reagent kit with gDNA eraser (PK02006, Takara Bio. Inc, Japan). These primers for selected genes were designed based on the Tea Plant Information Archive (http://tpia.teaplant.org/index.html) and

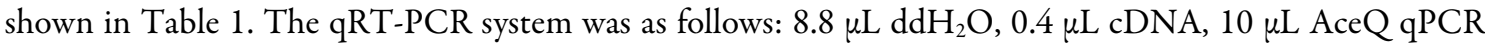
SYBR Green Master Mix, $0.4 \mu \mathrm{L}$ forward prime, and $0.4 \mu \mathrm{L}$ reverse prime. qRT-PCR were run on a CFX96 Real Time PCR Detection System (BIO-RAD, USA) under the following conditions: $95^{\circ} \mathrm{C}$ for $5 \mathrm{~min}, 40 \mathrm{cycles}$ with $95^{\circ} \mathrm{C}$ for $10 \mathrm{~s}$, and $60^{\circ} \mathrm{C}$ for $30 \mathrm{~s}$. qRT-PCR determinations were performed on 3 independent biological samples with 2 technical replications for each sample were examined. Quantification of the gene expression was done with the $2^{-\Delta \Delta C t}$ method (Livak and Schmittgen, 2001) in which the housekeeping gene (GADPH) acted as the control. The measured transcripts were normalized to the relative expression value in non-AMFcolonized plants grown without shade.

Table 1. The specific primers of relevant genes designed for real time quantitative PCR amplification

\begin{tabular}{|c|c|c|c|}
\hline Gene name & Accession & Sequence $\left(5^{\prime}-3^{\prime}\right)$-forward & Sequence $\left(5^{\prime}-3^{\prime}\right)$-reverse \\
\hline$C s C P C$ & TEA002005 & ATTGTTTTGTGGGTGTGGT & TCATCCATGGAAACCTGTGA \\
\hline$C s T T G 1$ & TEA000080 & GGAAATGATGCAAGGAGGAA & CCAATTATGGATTGGGCATC \\
\hline$C s A U X 1$ & TEA019802 & TCTGGGGAAGAGCAGAGTGT & TTGGCACCATCATGTTCTGT \\
\hline$C s Y U C C A 1$ & TEA020169 & TTCACCTCCCCAAACAGTTC & CCCCATTTCCATGATCAAAC \\
\hline$C s N C E D 2$ & TEA025155 & ACCGGACTCAATTTTCAACG & CTCGCCACCGTATTTTTCAT \\
\hline$C s G A 3 O X 1$ & TEA001361 & GGGTTGTGGGCTGTAAAAGA & AGATGTCAGTGCGAGTGTCG \\
\hline$C s D W F 4$ & TEA019686 & GTTGCCTGAGGTTGAGAAGC & GGGGAAGCAATTTGAAAACA \\
\hline$C s A O S$ & TEA001041 & CTTCCGTATCCGAAAGACCA & CTCTTGCCGTCCAGAAGAAC \\
\hline$C s G A D P H$ & TEA003029 & TTGGCATCGTTGAGGGTCT & CAGTGGGAACACGGAAAGC \\
\hline
\end{tabular}




\section{Statistical analysis}

The data were statistical analyzed by the two-factor variance (ANOVA) (SAS software 8.1), and the significant differences between treatments were compared with the Duncan's multiple range tests at $P<0.05$.

\section{Results}

\section{Plant growth performance}

As shown in Figure 1, shade had avoided tea plants' sunburn damage observably. Furthermore, Glomus etunicatum was beneficial to tea plant growth especially in shade condition (Figure 1). Plant height, shoot and root biomass were significantly increased in the shade treatments compared to the non-shade treatments, irrespective of AMF status (Table 2). Compared with non-AMF treatments, G. etunicatum treatments significantly increased plant height by $38.9 \%$ and $40.2 \%$, shoot biomass by $40.2 \%$ and $50.4 \%$, and root biomass by $36.9 \%$ and $143 \%$ under shade and non-shade conditions (Table 2).

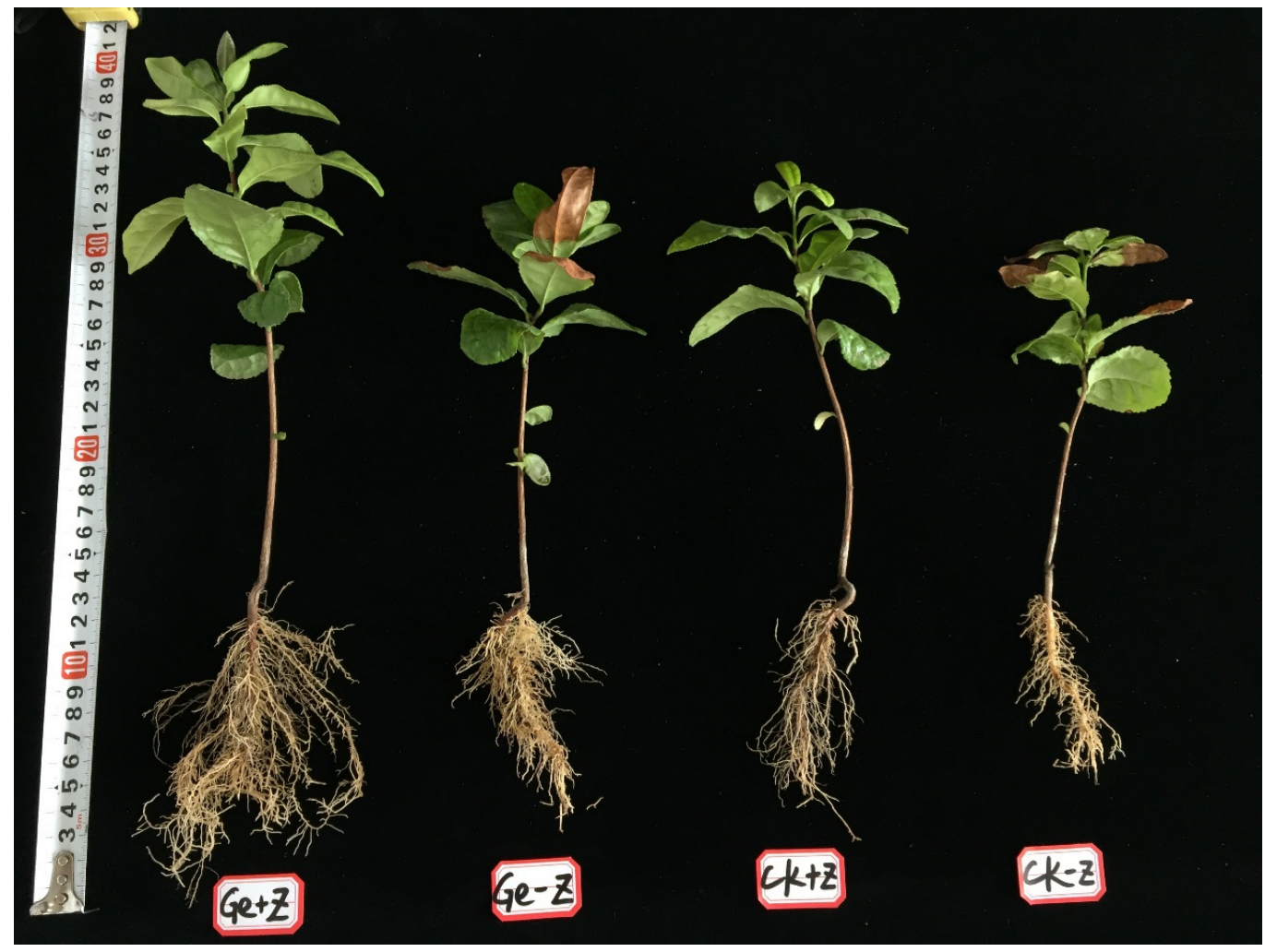

Figure 1. Whole root morphology in Camellia sinensis 'Xinyang population' seedlings colonized by Glomus etunicatum $(\mathrm{Ge})$ under shade $(+\mathrm{Z})$ and non-shade $(-\mathrm{Z})$ conditions 
Table 2. Effects of Glomus etunicatum (Ge) on root AMF colonization and growth performance of Camellia sinensis 'Xinyang population' seedlings grown in simulated shade $(+Z)$ and non-shade $(-Z)$

\begin{tabular}{|c|c|c|c|c|}
\hline Treatments & $\begin{array}{c}\text { Root mycorrhizal } \\
\text { colonization }(\%)\end{array}$ & $\begin{array}{c}\text { Plant height } \\
(\mathrm{cm})\end{array}$ & $\begin{array}{c}\text { Shoot biomass } \\
(\mathrm{g} \mathrm{FW} / \text { plant })\end{array}$ & $\begin{array}{c}\text { Root biomass } \\
(\mathrm{g} \mathrm{FW} / \text { plant })\end{array}$ \\
\hline $\mathrm{Ge}+\mathrm{Z}$ & $48.0 \pm 5.4 \mathrm{a}$ & $25.33 \pm 0.75 \mathrm{a}$ & $2.51 \pm 0.19 \mathrm{a}$ & $1.89 \pm 0.14 \mathrm{a}$ \\
\hline $\mathrm{Ge}-\mathrm{Z}$ & $18.5 \pm 1.2 \mathrm{~b}$ & $18.48 \pm 1.52 \mathrm{~b}$ & $1.82 \pm 0.11 \mathrm{~b}$ & $1.41 \pm 0.06 \mathrm{~b}$ \\
\hline $\mathrm{CK}+\mathrm{Z}$ & $0.0 \pm 0.0 \mathrm{c}$ & $18.02 \pm 0.81 \mathrm{~b}$ & $1.79 \pm 0.19 \mathrm{~b}$ & $1.38 \pm 0.14 \mathrm{~b}$ \\
\hline $\mathrm{CK}-\mathrm{Z}$ & $0.0 \pm 0.0 \mathrm{c}$ & $13.18 \pm 1.41 \mathrm{c}$ & $1.21 \pm 0.08 \mathrm{c}$ & $0.58 \pm 0.08 \mathrm{c}$ \\
\hline
\end{tabular}

\section{Root mycorrhizal colonization}

There was mycorrhizal colonization found in roots of the AMF-treated tea seedlings. Also, there was observed to vary in response to both types of treatments, mycorrhization and shade. As shown in Table 2, the seedlings inoculated with Glomus etunicatum had $48.0 \%$ and $18.5 \%$ of root mycorrhizal colonization under shade and non-shade conditions, respectively.

\section{Root morphology}

AMF and shade seedlings displayed greater total root length and root volume (Figure 2). Compared with non-AMF treatment, Glomus etunicatum treatment increased total root length by $51.8 \%$ and $60.9 \%$, root volume by $111.6 \%$ and $35.3 \%$ under shade and non-shade conditions (Table 2). Compared with non-shade treatments, shade treatments increased total root length by $44.1 \%$ and $52.7 \%$, root volume by $89.6 \%$ and $17.4 \%$ under AMF and non-AMF treatments (Table 2).

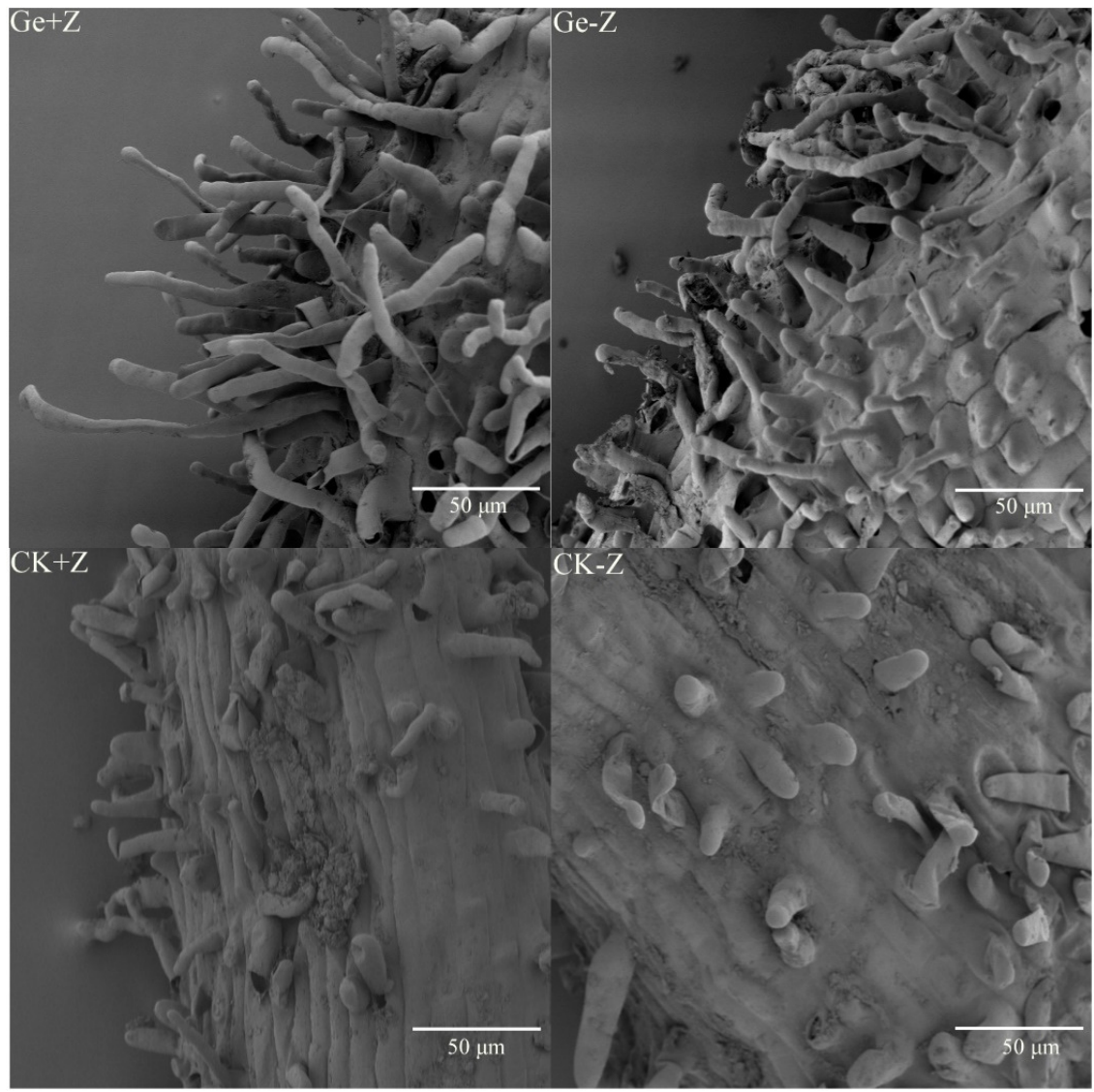

Figure 2. Whole root hairs morphology in Camellia sinensis 'Xinyang population' seedlings colonized by Glomus etunicatum $(\mathrm{Ge})$ under shade $(+\mathrm{Z})$ and non-shade $(-\mathrm{Z})$ conditions 
With regard to root hair, AMF and shade seedlings displayed remarkably greater root hair growth (Figure 2). As shown in Table 3, the root hair length and number of AMF-inoculation (50.21 $\mu \mathrm{m}$ and 52.97 $\times 10^{4} /$ plant) were significantly higher than non-AMF control $\left(38.89 \mu \mathrm{m}\right.$ and $40.01 \times 10^{4} /$ plant $)$ under shade treatments. However, root hair diameter had no significant difference between AMF and non-AMF treatments with shade treated (Table 3). These situations were as same as under non-shade condition (Figure 2, Table 3). Relative to non-shade control, root hair length and number were significantly increased in shade treatments irrespective of AMF status (Table 3). Root hair diameter, however, had no significant difference between shade and non-shade treatments under both AMF and non-AMF conditions (Table 3).

Table 3. Effects of Glomus etunicatum $(\mathrm{Ge})$ on root morphological traits of Camellia sinensis 'Xinyang population' seedlings grown in simulated shade $(+Z)$ and non-shade $(-Z)$

\begin{tabular}{|c|c|c|c|c|c|}
\hline \multirow{2}{*}{ Treatment } & \multirow{2}{*}{$\begin{array}{c}\text { Total root } \\
\text { length }(\mathrm{cm})\end{array}$} & \multirow{2}{*}{$\begin{array}{c}\text { Root volume } \\
\left(\mathrm{cm}^{3}\right)\end{array}$} & $\begin{array}{c}\text { Root hair } \\
\text { length }(\mu \mathrm{m})\end{array}$ & $\begin{array}{c}\text { Root hair } \\
\text { diameter }(\mu \mathrm{m})\end{array}$ & $\begin{array}{c}\text { Root hair number } \\
\left(\times 10^{4} / \text { plant }\right)\end{array}$ \\
\hline $\mathrm{Ge}+\mathrm{Z}$ & $255.95 \pm 16.28 \mathrm{a}$ & $2.18 \pm 0.16 \mathrm{a}$ & $50.21 \pm 3.23 \mathrm{a}$ & $11.89 \pm 1.01 \mathrm{a}$ & $52.97 \pm 4.01 \mathrm{a}$ \\
\hline $\mathrm{Ge}-\mathrm{Z}$ & $177.61 \pm 14.15 \mathrm{~b}$ & $1.15 \pm 0.11 \mathrm{bc}$ & $40.13 \pm 3.11 \mathrm{~b}$ & $10.74 \pm 1.02 \mathrm{ab}$ & $40.12 \pm 3.13 \mathrm{~b}$ \\
\hline $\mathrm{CK}+\mathrm{Z}$ & $168.34 \pm 15.10 \mathrm{~b}$ & $1.03 \pm 0.10 \mathrm{bc}$ & $38.89 \pm 3.56 \mathrm{~b}$ & $10.55 \pm 0.98 \mathrm{ab}$ & $40.01 \pm 3.89 \mathrm{~b}$ \\
\hline $\mathrm{CK}-\mathrm{Z}$ & $110.30 \pm 10.83 \mathrm{c}$ & $0.85 \pm 0.04 \mathrm{c}$ & $30.56 \pm 2.01 \mathrm{c}$ & $10.12 \pm 0.89 \mathrm{~b}$ & $25.53 \pm 2.12 \mathrm{c}$ \\
\hline
\end{tabular}

\section{Leaf nutrient concentrations}

Compared to the non-AMF inoculation, leaf $\mathrm{N}, \mathrm{P}, \mathrm{K}, \mathrm{Ca}, \mathrm{Mg}$ and $\mathrm{Fe}$ contents were significantly increased by $35.7,39.1,35.6,75.1,37.1$ and $20.0 \%$ with the inoculation of Glomus etunicatum under shade condition, respectively (Table 4). The promoting effects of AMF on tea leaf nutrient concentrations were as same as under non-shade condition (Table 4). However, no significant difference of leaf Fe levels was observed between AMF- and non-AMF-inoculated tea seedlings exposed to non-shade condition. Except Fe level in leaf, the concentration of $\mathrm{N}, \mathrm{P}, \mathrm{K}, \mathrm{Ca}$ and $\mathrm{Mg}$ were significantly increased in the shade treatment, compared to the non-shade treatments, irrespective of AMF status (Table 4).

Table 4. Effects of Glomus etunicatum (Ge) on leaf nutrient element content (mg/plant dry weight) of Camellia sinensis 'Xinyang population' seedlings grown in simulated shade $(+\mathrm{Z})$ and non-shade $(-\mathrm{Z})$

\begin{tabular}{|c|c|c|c|c|c|c|}
\hline Treatments & $\mathrm{N}$ & $\mathrm{P}$ & $\mathrm{K}$ & $\mathrm{Ca}$ & $\mathrm{Mg}$ & $\mathrm{Fe}$ \\
\hline $\mathrm{Ge}+\mathrm{Z}$ & $20.11 \pm 1.92 \mathrm{a}$ & $0.96 \pm 0.08 \mathrm{a}$ & $8.12 \pm 0.61 \mathrm{a}$ & $4.01 \pm 0.28 \mathrm{a}$ & $1.22 \pm 0.11 \mathrm{a}$ & $0.17 \pm 0.02 \mathrm{a}$ \\
\hline $\mathrm{Ge}-Z$ & $15.30 \pm 1.21 \mathrm{~b}$ & $0.72 \pm 0.07 \mathrm{~b}$ & $6.18 \pm 0.52 \mathrm{~b}$ & $2.39 \pm 0.21 \mathrm{~b}$ & $0.95 \pm 0.09 \mathrm{~b}$ & $0.16 \pm 0.01 \mathrm{ab}$ \\
\hline $\mathrm{CK}+\mathrm{Z}$ & $14.82 \pm 1.10 \mathrm{~b}$ & $0.69 \pm 0.05 \mathrm{~b}$ & $5.99 \pm 0.41 \mathrm{~b}$ & $2.29 \pm 0.25 \mathrm{~b}$ & $0.89 \pm 0.07 \mathrm{~b}$ & $0.15 \pm 0.01 \mathrm{~b}$ \\
\hline $\mathrm{CK}-\mathrm{Z}$ & $10.30 \pm 0.93 \mathrm{c}$ & $0.48 \pm 0.03 \mathrm{c}$ & $4.30 \pm 0.23 \mathrm{c}$ & $1.52 \pm 0.12 \mathrm{c}$ & $0.58 \pm 0.04 \mathrm{c}$ & $0.15 \pm 0.01 \mathrm{~b}$ \\
\hline
\end{tabular}

\section{Root phytohormones levels}

The tea seedlings' roots have been harvested for measuring the levels of phytohormones, such as auxin (IAA), abscisic acid (ABA), gibberellin (GA), Brassinolide (BR) and jasmonic acid (JA).

Compared with non-mycorrhizal seedlings, mycorrhizal seedlings had significantly higher levels of IAA, GA and BR under shade and non-shade treatments, but ABA and JA concentrations had no difference under shade condition (Table 5). However, the levels of ABA and JA of non-AMF-inoculated tea root were dramatically higher than AMF-inoculated root under non-shade condition (Table 5). Compared with nonshade treatment, shade treatment observably increased IAA level by $28.0 \%$ and $20.4 \%$, GA level by $39.9 \%$ and $34.4 \%$ and BR level by $21.8 \%$ and $13.0 \%$ under AMF and non-AMF treatments (Table 5). Furthermore, the levels of $\mathrm{ABA}$ and JA of non-AMF-inoculated under non-shade condition were the highest among 4 treatments. 
Table 5. Effects of Glomus etunicatum (Ge) on root endogenous phytohormones levels (ng/g FM) of Camellia sinensis 'Xinyang population' seedlings grown in simulated shade $(+\mathrm{Z})$ and non-shade $(-\mathrm{Z})$

\begin{tabular}{|c|c|c|c|c|c|}
\hline Treatments & IAA & GA & BR & ABA & JA \\
\hline Ge $+Z$ & $320.11 \pm 31.29 \mathrm{a}$ & $14.16 \pm 1.22 \mathrm{a}$ & $14.89 \pm 1.22 \mathrm{a}$ & $34.96 \pm 3.29 \mathrm{~b}$ & $13.22 \pm 1.56 \mathrm{~b}$ \\
\hline $\mathrm{Ge}-\mathrm{Z}$ & $250.30 \pm 24.22 \mathrm{~b}$ & $10.12 \pm 0.98 \mathrm{~b}$ & $12.22 \pm 1.13 \mathrm{~b}$ & $35.72 \pm 3.01 \mathrm{~b}$ & $13.95 \pm 1.22 \mathrm{~b}$ \\
\hline $\mathrm{CK}+\mathrm{Z}$ & $240.82 \pm 22.89 \mathrm{~b}$ & $10.91 \pm 1.01 \mathrm{~b}$ & $12.31 \pm 1.05 \mathrm{~b}$ & $34.69 \pm 3.22 \mathrm{~b}$ & $13.89 \pm 1.13 \mathrm{~b}$ \\
\hline $\mathrm{CK}-\mathrm{Z}$ & $200.82 \pm 18.20 \mathrm{c}$ & $8.12 \pm 0.66 \mathrm{c}$ & $10.89 \pm 1.12 \mathrm{c}$ & $40.28 \pm 2.89 \mathrm{a}$ & $16.84 \pm 1.01 \mathrm{a}$ \\
\hline
\end{tabular}

\section{Relative expression of genes in root}

The response of mycorrhized tea seedlings under shade and non-shade treatments were associated with diverse changes in expression of root CsCPC, CsTTG1, CsAUX1, CsYUCCA1, CsNCED2, CsGA3OX1, CsDWF3 and CsAOS.

Compared with non-mycorrhizal seedlings, mycorrhizal seedlings had significantly higher expressions of $C s C P C, C s A U X 1, C s G A 3 O X 1$ and $C s D W F 3$ under shade and non-shade treatments respectively (Figure 3). Compared with non-shade treatment, shade treatment observably increased $C s C P C$ expression by $33.3 \%$ and $40.0 \%, C s A U X 1$ expression by $33.3 \%$ and $90.0 \%, C s G A 3 O X 1$ expression by $42.8 \%$ and $120.0 \%$ and CsDWF3 expression by $30.8 \%$ and $30.0 \%$ under AMF and non-AMF treatments (Figure 3). However, the expression of root CsTTG1 has opposite change in 4 treatments. Compared with non-AMF treatment, AMF inoculation significantly down-regulated the expression level of root CSTTG1 by 0.43 times under shade condition and 0.20 times under non-shade condition (Figure 3).

Interestingly, the repressions of $C S N C E D 2$ and $C S A O S$ in root of none-AMF treated under non-shade were up-regulated remarkably in 4 treatments (Figure 3). However, there has no significant change of the expression of CsYUCCA1 in 4 treatments seedlings' root.

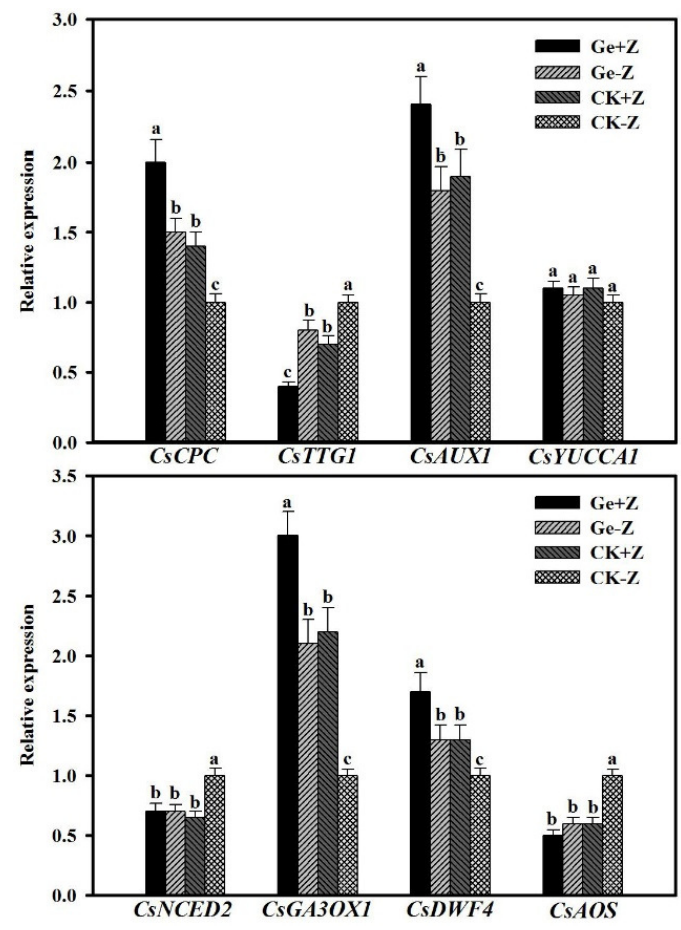

Figure 3. Effects of AMF inoculation and shade treatments on relative expression of root CsCPC, CsTTG1, CsAUX1, CsYUCCA1, CsNCED2, CsGA3OX1, CsDWF4 and CsAOS in Camellia sinensis 'Xinyang population' seedlings

Data (means \pm SD, $n=6$ ) are significantly different $(P<0.05)$ followed by different letters above the bars. 


\section{Discussion}

In the present study, the shade treatment significantly increased root AMF colonization than the nonshade treatment, which is in line with the earlier result as reported by Muleta et al. (2007) that notably higher mean counts of AMF spores were found under leguminous shade trees. In addition, AMF significantly increased tea plant growth (plant height, shoot and root biomass, leaf nutrient element content, total root length and volume, root hair growth, etc.) irrespective of shade status, which is in accord with the earlier results as reported by Shao et al. (2018). As is well-known, AMF can produce the hyphae network, which can help host plants to absorb nutrient and water from soil (Wu et al., 2013). AMF could also increase host plants' root biomass which enhanced the ability to absorb nutrient and water from soil (Wu et al., 2012, 2016; Upreti et al., 2016, Liu et al., 2018). Furthermore, root mycorrhizal colonization, total root length and volume were significantly positively correlated with leaf nutrient element content in this study. It can be seen from this, AMF helps the tea plant to absorb N, P, K, Ca and Mg by means of extraradical hyphae which generate from AMF, which was consistent with previous studies (Shao et al., 2018).

Besides, this study has confirmed that shade could avoid tea plants' sunburn damage (photosynthetic photon flux density was $1010 \mu \mathrm{mol} / \mathrm{m}^{2} / \mathrm{s}$, day/night temperature $36 / 23^{\circ} \mathrm{C}$ and relative air humidity $60 \%$ ). Plant height, leaf nutrient content, shoot and root biomass, total root length and volume were all significantly increased in the shade plants compared to the non-shade plants, which is in line with the earlier results as reported by Kalcsits et al. (2018) in apple. Root hair is tip-growing extensions from the root epidermis, which plays important roles in nutrient and water absorption (Zhang et al., 2013, 2018). Based on SEM photos, both of AMF and shade could stimulate root hair growth which was consistent with Zou et al. (2019). This study suggested that AMF and shade may stimulate the number of trihoblasts or the proportion of the bulges of root epidermis to root hairs which vastly increases root surface area and nutrient acquisition (Liu et al., 2018). So, their results suggest that AMF and shade-net could use in tea culture especially during summer for enhancing plants growth to against high temperature stress and sunburn damage.

To explore the mechanisms of AMF and shade enhance tea plants growth, this study analyzed the root endogenous phytohormones levels. Phytohormones including auxin (IAA), gibberellin (GA), brassinosteroid (BR), abscisic acid (ABA) and jasmonic acid (JA), regulate plant growth and development that could be affected by AMF and shading (Zhang et al., 2019; Li et al., 2019).

AMF-inoculation tea root had significantly higher levels of IAA, GA and BR than none-AMF treated plants' root, which is in line with the earlier results as reported by Zhang et al. (2019b) in trifoliate orange seedlings colonized by AMF (Funneliformis mosseae). Furthermore, shading root also has higher levels of IAA, GA and BR no matter in AMF or none-AMF condition. IAA, one of the best-known phytohormones, have an extremely wide spectrum of activity, and are particularly important in plant growth, such as root hair growth, root and shoot biomass (Zbigniew et al., 2018; Zhang et al., 2018). So, AMF and shading treated tea seedlings has vigorous growth may cause by increasing of endogenous IAA. GA and BR could promote stem elongation, which caused higher tea plant in AMF and shading treatments in this study (Yin et al., 2002; Li et al., 2018c). But there has no effect of AMF on ABA and JA concentrations under shade condition while AMF reduce its levels when treated with non-shade in this study. ABA and JA, as growth inhibitors that slows the growth of plant, which levels were negatively correlated with plant growth (such as plant height, root and shoot biomass, root hair growth, leaf nutrient concentrations, etc.) (Li et al., 2018d; Yang et al., 2018; Zhang et al., 2020).

In order to understand the molecular mechanism of these changes in tea plants roots, expression of root hair regulated genes and endogenous phytohormones biosynthesis and transport genes were measured. $C P C$ and TTG1 expression are related with root hair growth (Wada et al., 1997; Tominaga-Wada et al., 2016; Long and Schiefelbein, 2020). In the present study, mycorrhizal inoculation and shading significantly up-regulated the expression level of root CsCPC, which is positive regulation with root hair growth (Wada et al., 1997; Savage et al., 2013; Tominaga-Wada et al., 2016). It is in line with the result of the root hair's growth that mycorrhizal inoculation and shading notably increased the number and length of root hair in this study. With 
regards to the TTG1, Long and Schiefelbein (2020) has reported that it negatively regulates root hair formation in Arabidopsis. It is similar to tea plant in this study that higher expression of CsTTG1 in the treatments of non-mycorrhizal inoculation and non-shade accompanied by less and short root hairs. So, higher expression of CsCPC and lower expression of CsTTG1 potentially promoted the initiation and elongation of root hair in tea plants.

Indole-3-acetic acid (IAA), the predominant auxin in plants, plays a critical role in plant growth and developmental processes, its biosynthesis and transport has been clearly elucidated by YUCCA (encodes a flavin monooxygenase-like enzyme) and $A U X$ genes (Bennett et al., 1996; Zhao et al., 2001; Hoyerova et al., 2018; Kyoko et al., 2019). In the present study, mycorrhizal inoculation and shading notably up regulated the expression level of root CsAUX1, which regulate IAA transport (Bennett et al., 1996). It is in line with the result of the root IAA level in this study that mycorrhizal inoculation and shading significantly accelerated the transportation of IAA in root. However, mycorrhizal inoculation and shading have no significance differentiation in root CsYUCCA1 expression, which regulate IAA biosynthesis. Sieberer and Leyser (2006) have indicated that auxin synthesized in shoot apices then moved along specific transport routes through the plant by unique polar transport machinery. Jia et al. (2019) introduced the IAA reporter DR5ver2:GUS into wild strawberry (Fragaria vesca) to reveal auxin distribution in the seed and fruit receptacle pre- and postfertilization as well as in the root. Based on their results, it considered that both mycorrhizal inoculation and shading have no effect on IAA synthesize in root of tea seedlings. Further studies will be needed to identify the synthesize of IAA in tea plant.

The genes that participate in GA biosynthesis and affect plant growth and development has been extensively studied in planta (Schomburg et al., 2003). GA 3-oxidase, catalyse the final step of active GA biosynthesis, converting inactive forms of GA such as GA3ox catalyzes the breakdown of bioactive GAs (Roumeliotis et al., 2013). Roumeliotis et al. (2013) has cloned StGA3ox2 gene in an RNAi construct and used this construct to transform potato (Solanum tuberosum), which confirmed that GA3ox2 could catalysed the final step in GA biosynthesis, that convert inactive forms of GA into active $\mathrm{GA}_{1}$ and $\mathrm{GA}_{4}$. In this study, AMF and shading significantly up-regulated the relative expression of root $C s G A 3 O X 1$ and increased GA content, respectively. It concludes that both AMF and shading could up-regulate $C s G A 3 O X I$ to induce GA accumulation in tea root, which results in diverse phenotypes, such as longer plant height, dense root hairs and higher biomasses of root and shoot (Huang et al., 1998).

Brassinosteroid (BR) is essential plant-specific steroidal hormones, which refers to the growthpromoting steroids found in plants (Choe et al., 1998). DWF4, encodes a cytochrome $\mathrm{P} 450$ that mediates multiple 22alpha-hydroxylation steps in brassinosteroid biosynthesis (Choe et al., 1998; Li et al., 2018a). In the present study, AMF and shading significantly up-regulated the relative expression of root CsDWF4 and increased the level of BRs in tea root. Therefore, it concludes that AMF and shading up-regulated CsDWF4to induce BR accumulation in root respectively, which results in same phenotypes to GAs. It is in line with the result reported by Shahnejat-Bushehri et al. (2016) in Arabidopsis.

Abscisic acid (ABA), the growth inhibitor, is another plant hormone that has regulatory roles during plant growth and development (Leng et al., 2014). ABA biosynthesis requires the cleavage of C40 carotenoids by 9-cis-epoxycarotenoid dehydrogenase (NCED) to form its direct precursor (xanthoxin), which process is a key rate-limiting step in ABA biosynthesis (Estrada-Melo et al., 2015). Transgenic tomato (Solanum lycopersicum) to silence SINCED1 exhibited reduced endogenous ABA level while PpNCED2/3 positively regulates ABA biosynthesis in peach (Prunus persica) (Sun et al., 2012; Wang et al., 2019). In the present study, mycorrhizal inoculation and shading significantly down-regulated the relative expression of root CSNCED2. It concludes that both $\mathrm{AMF}$ and shading down-regulated $C S N C E D 2$ to reduce $\mathrm{ABA}$ accumulation. So, $\mathrm{ABA}$ levels of tea plants were lower whether in mycorrhizal inoculation or shading treated in this study, compared with non-mycorrhizal seedlings under non-shading condition.

Jasmonic acid (JA), as another plant growth inhibitor, plays a regulatory role in plant responses to environmental and developmental cues such as blocked root elongation and pericarp development, inhibited 
protein phosphatase activity and epicotyl growth (Kato-Noguchi et al., 2009; Martin et al., 2009; Gutierrez et al., 2012; Lian et al., 2013). Allene oxide synthase (AOS), is the key enzymes involved in jasmonic acid biosynthesis in plants, leading to an unstable allene oxide (Lian et al., 2013). Lian et al. (2013) isloated GhAOS and confirmed that it is the key gene in regulating jasmonic acid biosynthesis in Gladiolus hybridus. In this study, AMF and shading significantly down-regulated the relative expression of root $C S A O S$ and decreased JA level, respectively. Therefore, it could be speculated that AMF and shading down-regulated CsAOS to suppress JA biosynthesis, which results in promoting tea plants growth.

\section{Conclusions}

AMF and shading seedlings recorded higher plant growth performance (plant height, shoot biomass and leaf nutrients content except $\mathrm{Fe}$ ) and root morphology (root biomass, total root length and volume) than nonAMF or non-shading seedlings. AMF and shading significantly increased root hair growth, in company with up-regulation of positive regulation root hair growth gene $C s C P C$ and down-regulation of negative regulation root hair growth gene CsTTG1. Root auxin level and transport gene $C s A U X 1$ was up-regulated by AMF and shading. Interestingly, auxin biosynthesis gene CsYUCCAI has not been affected, which suggested that both AMF and shading mainly regulate auxin transport but not biosynthesis pathway. The contents of GA and BR in root were notably increased by AMF and shading, accompanied with up-regulation of its biosynthesis genes, CsGA3OX1 and CSDWF4. With regard to the growth inhibiting phytohormones ABA and JA, our results showed that AMF and shading significantly decreased its levels in root, in company with down-regulation of its biosynthesis genes, CSNCED2 and CSAOS. These results implied that AMF and shading could resist high temperature and strong light stress that had positive effects on tea plant growth, nutrient absorption, especially in roots through improving root hair growth and increasing the contents of root positively phytohormones by up-regulating its transport and biosynthesis pathway. Such results will provide a clear path to manage tea plants in field for roots and mycorrhizas in shading condition.

\section{Authors' Contributions}

Conceptualization: DJZ and YYL; Data curation:MFS, DY and XCH; Formal analysis: MFS and XCH; Funding acquisition: DJZ and YYL; Investigation: MFS and DY; Project administration: DJZ and YYL; Supervision: DJZ; Writing - original draft: MFS and DY; Writing -review and editing: DJZ and YYL. All authors read and approved the final manuscript.

\section{Acknowledgements}

This work was supported by The Open Fund of Henan Key Laboratory of Tea Comprehensive utilization in South Henan (HNKLTOF2019004, Xinyang Agriculture and Forestry University) and the Open Fund of State Key Laboratory of Tea Plant Biology and Utilization (SKLTOF20180113, Anhui Agricultural University). 
Sun M et al. (2020). Not Bot Horti Agrobo 48(4):2006-202

\section{Conflict of Interests}

The authors declare that there are no conflicts of interest related to this article.

\section{References}

Aliasgharzad N, Hajiboland R, Olsson PA (2011). Lack of arbuscular mycorrhizal colonisation in tea (Camellia sinensis L.) plants cultivated in Northern Iran. Symbiosis 55:91-95.

Bray DF, Bagu J, Koegler P (1993). Comparison of hexamethyldisilazane (HMDS), Peldri II, and critical-point drying methods for scanning electron microscopy of biological specimens. Microscopy Research and Technique 26:489-495. https://doi.org/10.1002/jemt.1070260603

Bennett MJ, Marchant A, Green HG, May ST, Ward SP, ... Feldmann KA (1996). Arabidopsis AUX1 gene: a permease-like regulator of root gravitropism. Science 273:948-950. https://doi.org/10.1126/science.273.5277.948

Choe S, Dilkes BP, Fujioka S, Takatsuto S, Sakurai A, Feldmann KA (1998). The DWF4 gene of Arabidopsis encodes a cytochrome P450 that mediates multiple 22alpha-hydroxylation steps in brassinosteroid biosynthesis. The Plant Cell 10:231-244. https://doi.org/10.1105/tpc.10.2.231

Estrada-Melo AC, Reid MS, Jiang CZ (2015). Overexpression of an ABA biosynthesis gene using a stress-inducible promoter enhances drought resistance in petunia. Horticulture Research 2:15013. https://doi.org/10.1038/hortres.2015.13

Gutierrez L, Mongelard G, Flokova K, Pacurar DI, Novák O, ... Bellini C (2012). Auxin controls Arabidopsis adventitious root initiation by regulating jasmonic acid homeostasis. The Plant Cell 24:2515-2527. https://doi.org/10.1105/tpc.112.099119

Hashem A, Alqarawi AA, Al-Huqail AA, AbdAllah EF (2018). Biodiversity of arbuscular mycorrhizal fungi associated with Acacia gerrardii Benth in different habitats of Saudi Arabia. Pakistan Journal of Botany 50:1211-1217.

Hoyerova K, Hosek P, Quareshy M, Li J, Klima P, Kubes M, ... Napier RM (2018). Auxin molecular field maps define AUXI selectivity: many auxin herbicides are not substrates. New Phytologist 217:1625-1639. https://doi.org/10.1111/nph.14950

Huang S, Raman AS, Ream JE, Fujiwara H, Cerny RE, Brown SM (1998). Overexpression of 20-oxidase confers a gibberellinoverproduction phenotype in Arabidopsis. Plant Physiologist 118:773-781. https://doi.org/10.1104/pp.118.3.773

Jia F, Cheng D, Huifeng L, Yafan H, Zhongchi L, Chunying K (2019). Reporter gene expression reveals precise auxin synthesis sites during fruit and root development in wild strawberry. Journal of Experimental Botany 70:563-574. https://doi.org/10.1093/jxb/ery384

Kahneh E, RamezanPour H, Tanha MRH, Shirinfekr A (2006). Effect of arbuscular mycorrhizal fungi and phosphorus supplement on leaf $\mathrm{P}, \mathrm{Zn}, \mathrm{Cu}$ and Fe concentrations of tea seedlings. Caspian Journal of Environmental Science 4:5358. http://dx.doi.org/10.4067/S0718-95162014005000016

Kalcsits L, Asteggiano L, Schmidt T, Musacchi S, Serra S, Layne DR, ... Mupambi G (2018). Shade netting reduces sunburn damage and soil moisture depletion in 'Granny Smith' apples. Acta Horticulturae 1228:85-90. https://doi.org/10.17660/ActaHortic.2018.1228.11

Kato-Noguchi H, Kobayashi K (2009). Jasmonic acid, protein phosphatase inhibitor, metals and UV-irradiation increased momilactone A and B concentrations in the moss Hypnum plumaeforme. Journal of Plant Physiology 166:1118-1122. https://doi.org/10.1016/j.jplph.2008.12.012

Kojima M, Sakakibara H (2012). Highly sensitive high-throughput profiling of six phytohormones using MS-probe modification and liquid chromatography-tandem mass spectrometry. Methods in Molecular Biology 918:151-164. https://doi.org/10.1007/978-1-61779-995-2_11

Ohashi-Ito K, Iwamoto K, Nagashima Y, Kojima M, Sakakibara H, Fukuda H (2019). A positive feedback loop comprising LHW-TMO5 and local auxin biosynthesis regulates initial vascular development in Arabidopsis roots. Plant and Cell Physiology 60(12):2684-2691. https://doi.org/10.1093/pcp/pcz156

Lagad RA, Alamelu D, Laskar AH, Rai VK, Singhb SK, Aggarwal SK (2013). Isotope signature study of the tea samples produced at four different regions in India. Analytical Methods 5:1604-1611.

Leng P, Yuan B, Guo Y (2014). The role of abscisic acid in fruit ripening and responses to abiotic stress. Journal of Experimental Botany 65:4577-4588. https://doiorg/10.1093/jxb/eru204 
Li Q, Yu JW, Lu J, Fei HY, Luo M, Cao BW, ... Liu QQ (2018a). Seed-specific expression of OsDWF4, a rate-limiting gene involved in BR biosynthesis, improves both grain yield and quality in rice. Journal of Agricultural and Food Chemistry 66:3759-3772. https://doi.org/10.1021/acs.jafc.8b00077

Li T, Dai J, Zhang Y, Kong X, Li C, Dong H (2019). Topical shading substantially inhibits vegetative branching by altering leaf photosynthesis and hormone contents of cotton plants. Field Crops Research 238:18-26. https://doi.org/10.1016/j.fcr.2019.04.019

Li X, Wei JP, Ahammed GJ (2018b). Brassinosteroids attenuate moderate high temperature-caused decline in tea quality by enhancing the anine biosynthesis in Camellia sinensis L. Frontiers in Plant Science 9:1016. https://doi.org/10.3389/fpls.2018.01016

Li YX, Tang DY, Li L, Zhao XY, Lin JZ, Liu XM (2018c). Plant stature related receptor-like Kinanse2 (PSRK2) acts as a factor that determines stem elongation toward gibberellins response in rice. Bioscience Biotechnology and Biochemistry 82:1931-1941. https://doi.org/10.1080/09168451.2018.1501266

Li Z, Takahashi Y, Scavo A, Brandt B, Nguyen D, Rieu P, Schroeder JI (2018d). Abscisic acid-induced degradation of Arabidopsis guanine nucleotide exchange factor requires calcium-dependent protein kinases. Proceedings of the National Academy of Sciences 115:4522-4531. https://doi.org/10.1073/pnas.1719659115

Lian QL, Xin HB, Li XX, Zhong XH, Yin YL, Yi MF (2013). Isolation, characterization and expression analysis of the genesGhAOS, GhAOC and GhOPR3: Encoding the key enzymes involved in jasmonic acid biosynthesis in Gladiolus hybridus. Scientia Horticulturae 154:88-95.

Lin ZH, Qi YP, Chen RB, Zhang FZ, Chen LS (2010). Effects of phosphorus supply on the quality of green tea. Food Chemistry 130:908-914.

Liu CY, Zhang F, Zhang DJ, Srivastava AK, Wu QS, Zou YN (2018). Mycorrhiza stimulates root-hair growth and IAA synthesis and transport in trifoliate orange under drought stress. Scientific Reports 8:1978.

Livak KJ, Schmittgen TD (2001). Analysis of relative gene expression data using real-time quantitative PCR and $2^{-\Delta \Delta \mathrm{Ct}}$ method. Methods 25:402-408. https://doi.org/10.1006/meth.2001.1262

Long Y, Schiefelbein J (2020). Novel ttg1 mutants modify root-hair pattern formation in Arabidopsis. Frontiers in Plant Science 11:383. https://doi.org/10.3389/fpls.2020.00383

Martin MT, Pedranzani H, Garcia-Molinero P, Pando V, Sierra-de-Grado R (2009). Inhibitory effect of jasmonic acid and ethylene on epicotyl growth and bud induction in the maritime pine, Pinus pinaster Soland. in Ait. Biocell 33:141-148. https://doi.org/10.32604/biocell.2009.33.141

Mathur S, Sharma MP, Jajoo A (2018). Improved photosynthetic efficacy of maize (Zea mays) plants with arbuscular mycorrhizal fungi (AMF) under high temperature stress. Journal of Photochemistry and Photobiology B-Biology 180:149-154. https://doi.org/10.1016/j.jphotobiol.2018.02.002

Mathur S, Tomar RS, Jajoo A (2019). Arbuscular Mycorrhizal fungi (AMF) protects photosynthetic apparatus of wheat under drought stress. Photosynthesis Research 139:227-238. https://doi.org/10.1007/s11120-018-0538-4

Muleta D, Assefa F, Nemomissa S, Granhall U (2007). Composition of coffee shade tree species and density of indigenous arbuscular mycorrhizal fungi (AMF) spores in Bonga natural coffee forest, southwestern Ethiopia. Forest Ecology and Management 241:145-154. https://doi.org/10.1016/j.foreco.2007.01.021

Roumeliotis E, Kloosterman B, Oortwijn M, Lange T, Visser RGF, Bachem CWB (2013). Down regulation of StGA3oxgenes in potato results in altered GA content and affect plant and tuber growth characteristics. Journal of Plant Physiology 170:1228-1234.

Savage N, Yang TJ, Chen CY, Lin KL, Monk NA, Schmidt W (2013). Positional signaling and expression of ENHANCER OF TRY AND CPC1 are tuned to increase root hair density in response to phosphate deficiency in Arabidopsis thaliana. PLoS One 8:e75452. https://doi.org/10.1371/journal.pone.0075452

Schomburg FM, Bizzell CM, Lee DJ, Zeevaart JAD, Amasino RM (2003). Overexpression of a novel class of gibberellin 2oxidases decreases gibberellin levels and creates dwarf plants. The Plant Cell 15:151-163. https://doi.org/10.1105/tpc.005975

Shahnejat-Bushehri S, Tarkowska D, Sakuraba Y, Balazadeh S (2016). Arabidopsis NAC transcription factor JUB1 regulates GA/BR metabolism and signalling. Nature Plants 2:16013. https://doi.org/10.1038/nplants.2016.13

Shao YD, Zhang DJ, Hu XC, Wu QS, Jiang CJ, ... Kuca K(2018). Mycorrhiza-induced changes in root growth and nutrient absorption of tea plants. Plant, Soil and Environment 64:283-289. https://doi.org/10.17221/126/2018-PSE 
Sharma D, Kayang H (2017). Effects of arbuscular mycorrhizal fungi (AMF) on Camellia sinensis (L.) O. Kuntze under greenhouse conditions. Journal of Experimental Biology 5:235-241. http://dx.doi.org/10.18006/2017.5(2).235.241

Sieberer T, Leyser O (2006). Auxin transport, but in which direction? Many aspects of plant growth depend on transport of the hormone auxin across tissues, directed by specific transporter proteins. Science 312:858-860. https://doi.org/10.1126/science.1123701

Singh S, Pandey A, Chaurasia B, Palni LMS (2008). Diversity of arbuscular mycorrhizal fungi associated with the rhizosphere of tea growing in 'natural' and 'cultivated' ecosites. Biology and Fertility of Soils 44:491-500. https://doi.org/10.1007/s00374-007-0231-9

Sun L, Yuan B, Zhang M, Wang L, Cui M (2012). Fruit-specific RNAi-mediated suppression of SINCED1 increases both lycopene and $\beta$-carotene contents in tomato fruit. Journal of Experimental Botany 63:3097-3108. https://doi.org/10.1093/jxb/ers026

Tang H, TangJC, Li JL (2008). Synthetical effects of shading on tea plantation during the high-temperature and drought season. Guangdong Agriculture Science 26:26-29 (in Chinese with English abstract).

Tominaga-Wada R, Wada T (2016). Analysis of TTG1 and CPC-like MYB genes during Arabidopsis epidermal cell differentiation. Plant Biotechnology 33:201-206. https://doi.org/10.5511/plantbiotechnology.16.0629a

Upreti KK, Bhatt RM, Panneerselvam P, Varalakshmi LR (2016). Morpho-physiological responses of grape rootstock 'Dogridge' to arbuscular mycorrhizal fungi inoculation under salinity stress. International Journal of Fruit Science 16:191-209.

Wada T, Tachibana T, Shimura Y, Okada K (1997). Epidermal cell differentiation in Arabidopsis determined by a Myb homolog, CPC. Science 277:1113-1116. https://doi.org/10.1126/science.277.5329.1113

Wang X, Zeng W, Ding Y, Wang Y, Niu L, Pan L, ... Wang ZQ (2019). PpERF3 positively regulates ABA biosynthesis by activating $P$ PNCED2/3 transcription during fruit ripening in peach. Horticulture Research 6:19. https://doi.org/10.1038/s41438-018-0094-2

Wu QS, He JD, Srivastava AK, Zou YN, Kuca K (2019). Mycorrhizas enhance drought tolerance of citrus by altering root fatty acid compositions and their saturation levels. Tree Physiology 39:1149-1158. https://doi.org/10.1093/treephys/tpz039

Wu QS, He XH, Zou YN, Liu CY, Xiao J, Li Y (2012). Arbuscular mycorrhizas alter root system architecture of Citrus tangerine through regulating metabolism of endogenous polyamines. Plant Growth Regulation 68:27-35. https://doi.org/10.1007\%2Fs10725-012-9690-6

Wu QS, Liu CY, Zhang DJ, Zou YN, He XH, Wu QH (2016). Mycorrhiza alters the profile of root hairs in trifoliate orange. Mycorrhiza 26:237-247.

Wu QS, Srivastava AK, Zou YN (2013). AMF-induced tolerance to drought stress in citrus: A review. Scientia Horticulturae 164:77-87. https://doi.org/10.1016/j.scienta.2013.09.010

Wu QS, Zou YN, He XH, Luo P (2011). Arbuscular mycorrhizal fungi can alter some root characters and physiological status in trifoliate orange (Poncirus trifoliata L. Raf.) seedlings. Plant Growth Regulation 65:273-278. https://doi.org/10.1007/s10725-011-9598-6

Yang T, Lv R, Li J, Lin H, Xi D (2018). Phytochrome A and B negatively regulate salt stress tolerance of Nicotiana tabacum via ABA-Jasmonic acid synergistic cross-talk. Plant and Cell Physiology 59:2381-2393. https://doi.org/10.1093/pcp/pcy164

Yin Y, Wang ZY, Mora-Garcia S, Li JM, Yoshida S, Asami T, Chory J (2002). BES1 accumulates in the nucleus in response to brassinosteroids to regulate gene expression and promote stem elongation. Cell 109:181-191. https://doi.org/10.1016/s0092-8674(02)00721-3

Zbigniew B, Agnieszka S, Zenon T, Kurtyka R, Karcz W (2018). Role of auxin (IAA) in the regulation of slow vacuolar (SV) channels and the volume of red beet taproot vacuole. BMC Plant Biology 18:102. https://doi.org/10.1186/s12870-0181321-6

Zhang DJ, Xia RX, Cao X (2016). Ethylene modulates root hair development in trifoliate orange through auxin-signaling pathway. Scientia Horticulturae 213:252-259. https://doi.org/10.1016/j.scienta.2016.11.007

Zhang DJ, Xia RX, Cao X, Shu B, Chen CC (2013). Root hair development of Poncirus trifoliata grown in different growth cultures and treated with 3-indolebutyric acid and ethephon. Scientia Horticulturae 160:389-397. https://doi.org/10.1016/j.scienta.2013.06.007

Zhang DJ, Yang YJ, Liu CY, Zhang F, Hu W, ... Wu QS (2018). Auxin modulates root-hair growth through its signaling pathway in citrus. Scientia Horticulturae 236:73-78. 
Zhang F, Wang P, Zou YN, Wu QS, Kuca K (2019). Effects of mycorrhizal fungi on root-hair growth and hormone levels of taproot and lateral roots in trifoliate orange under drought stress. Archives of Agronomy and Soil Science 65:1316-1330. https://doi.org/10.1080/03650340.2018.1563780

ZhangJ, Zhang X, Ye M, LiXW, Lin SB, Sun XL (2020). The jasmonic acid pathway positively regulates the polyphenol oxidasebased defense against tea geometrid caterpillars in the tea plant (Camellia sinensis). Journal of Chemical Ecology 46:308316. https://doi.org/10.1007/s10886-020-01158-6

Zhang YC, Wang P, Wu QH, Zou YN, Bao Q, Wu QS (2017). Arbuscular mycorrhizas improve plant growth and soil structure in trifoliate orange under salt stress. Archives of Agronomy and Soil Science 63:491-500. https://doi.org/10.1080/03650340.2016.1222609

Zhao Y, Christensen SK, Fankhauser C, Cashman JR, Cohen JD, Chory J (2001). A role for flavin monooxygenase-like enzymes in auxin biosynthesis. Science 291:306-309. https://doi.org/10.1126/science.291.5502.306

Zou YN, Wang P, Liu CY, Ni QD, Zhang DJ, Wu QS (2017). Mycorrhizal trifoliate orange has greater root adaptation of morphology and phytohormones in response to drought stress. Scientific Reports 7:41134.

Zou YN, Wu HH, Giri B, Wu QS, Kuca K (2019). Mycorrhizal symbiosis down-regulates or does not change root aquaporin expression in trifoliate orange under drought stress. Plant Physiology and Biochemistry 144:292-299. https://doi.org/10.1016/j.plaphy.2019.10.001

Zou YN, Zhang DJ, Liu CY, Wu QS (2019). Relationships between mycorrhizae and root hairs. Pakistan Journal of Botany 5:727-733.
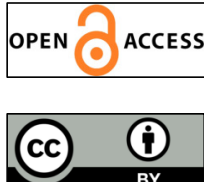

The journal offers free, immediate, and unrestricted access to peer-reviewed research and scholarly work. Users are allowed to read, download, copy, distribute, print, search, or link to the full texts of the articles, or use them for any other lawful purpose, without asking prior permission from the publisher or the author.

License - Articles published in Notulae Botanicae Horti Agrobotanici Cluj-Napoca are Open-Access, distributed under the terms and conditions of the Creative Commons Attribution (CC BY 4.0) License.

(c) Articles by the authors; UASVM, Cluj-Napoca, Romania. The journal allows the author(s) to hold the copyright/to retain publishing rights without restriction. 